\title{
Antibiotic Susceptibility as a Taxonomic Characteristic of the Genus Bacillus
}

\author{
O. N. REVA, V. A. VYUNITSKAYA, S. R. REZNIK, I. A. KOZACHKO, AND V. V. SMIRNOV* \\ Institute of Microbiology and Virology, Academy of Sciences, Kiev, Ukraine
}

\begin{abstract}
A large number of Bacillus strains assigned to different species were tested to determine their susceptibilities to antibiotics. Some clear differences between species were observed. The antibiotic susceptibilities of strains isolated from natural sources seemed to be stable and to reflect adaptation of the strains to specific conditions in certain ecological niches. A method for data processing which can be used for rapid species identification is described.
\end{abstract}

Bacteria belonging to the genus Bacillus are among the most widely distributed microorganisms and play significant roles in microbial communities. Nevertheless, species identification of microorganisms belonging to the genus Bacillus is very difficult because of the extreme phenotypic variability of these organisms. The most complete characterization of Bacillus species has been published by Priest et al. $(9,10)$. It is notable that the number of phenotypic tests by which the species can clearly be distinguished from each other is very small.

The susceptibility of bacilli to different antibiotics has been studied previously, and it has been demonstrated that in principle it should be possible to identify species on the basis of the results of susceptibility tests $(3,4,6,7,11)$. However, a simple method for data processing has not been available previously.

The instability of the plasmids that are present in Bacillus cells can cause doubts concerning the taxonomic value of susceptibility to antibiotics $(1,8,10)$. Previously, it was thought that the resistance of natural isolates was a stable property because it reflected adaptation of strains to conditions in specific ecological niches occupied by certain species.

The purpose of this study was to develop a method for identification based on a statistical evaluation of species differences in antibiotic susceptibility.

In this study we used 110 strains belonging to 17 species of the genus Bacillus. Species were identified as described by Claus and Berkeley (5) by using the following characteristics: cellular and spore morphology; Voges-Proskauer test; nitrate reduction to nitrite; anaerobic growth; gas production from nitrate and glucose; starch, urea, and casein degradation; acid production from glucose, galactose, lactose, mannose, and mannitol; utilization of citrate, acetate, lactate, and malonate; phenylalanine deamination; and arginine dihydrolase activity.

The test used to determine antibiotic susceptibility was performed by the disk agar diffusion method on Gause-2 medium containing (per liter of distilled water) $30 \mathrm{ml}$ of Chottinger broth, $5 \mathrm{~g}$ of peptone, $5 \mathrm{~g}$ of $\mathrm{NaCl}, 10 \mathrm{~g}$ of glucose, and $15 \mathrm{~g}$ of agar.

The nutrient medium was poured into $100-\mathrm{mm}$ petri dishes. Then cultures were grown overnight on the nutrient agar at $37^{\circ} \mathrm{C}$ and were used to prepare suspensions having an optical density of $5 \mathrm{U}$ (about 500,000 cells per $\mathrm{ml}$ ). A $0.1-\mathrm{ml}$ portion of each suspension was plated onto agar, and disks containing antibiotics were placed onto the surface of the medium. The cultures were incubated overnight at $37^{\circ} \mathrm{C}$. After incubation the diameters of the zones of growth inhibition were measured. Disks containing monomycin ( $30 \mu \mathrm{g}$ per disk), oleandomycin $(15 \mu \mathrm{g})$, oxacillin $(10 \mu \mathrm{g})$, ristomycin $(30 \mu \mathrm{g})$, gentamicin $(10$ $\mu \mathrm{g})$, chloramphenicol $(30 \mu \mathrm{g})$, ampicillin $(10 \mu \mathrm{g})$, erythromycin $(15 \mu \mathrm{g})$, polymyxin $(300 \mathrm{U})$, kanamycin $(30 \mu \mathrm{g})$, lincomycin $(15 \mu \mathrm{g})$, carbenicillin $(25 \mu \mathrm{g})$, methicillin $(10 \mu \mathrm{g})$, neomycin $(30 \mu \mathrm{g})$, tetracycline $(30 \mu \mathrm{g})$, streptomycin $(30 \mu \mathrm{g})$, and benzylpenicillin $(10 \mathrm{U})$ were used.

On the basis of the results of our identification tests, 75 fresh Bacillus strains were placed in the following six species: Bacillus subtilis, Bacillus licheniformis, Bacillus pumilus, Bacillus cereus, Bacillus megaterium, and Bacillus polymyxa.

TABLE 1. Means and standard deviations of inhibition zone diameters ${ }^{a}$

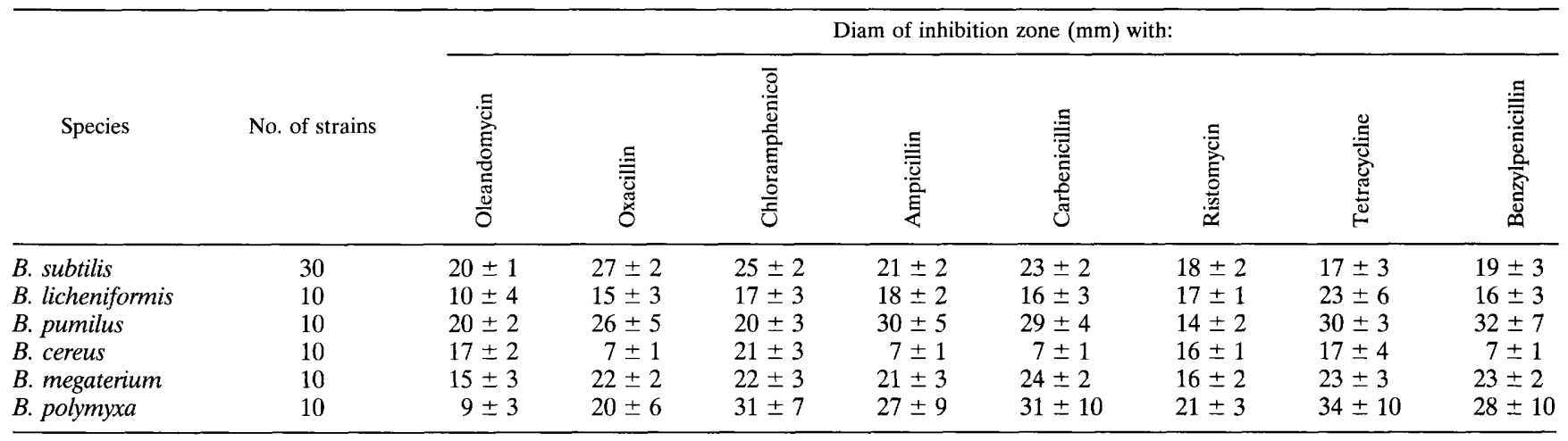

${ }^{a}$ Standard deviations were calculated for $P=0.99$.

\footnotetext{
* Corresponding author.
} 
TABLE 2. Coefficients of linear discriminant functions

\begin{tabular}{|c|c|c|c|c|c|c|c|c|}
\hline \multirow[b]{2}{*}{ Function } & \multicolumn{8}{|c|}{ Coefficient with: } \\
\hline & 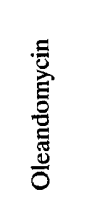 & 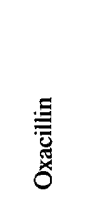 & 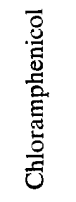 & $\frac{\Xi}{\stackrel{\Xi}{0}}$ & 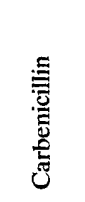 & 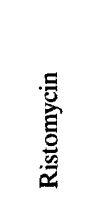 & 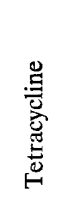 & 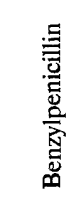 \\
\hline First & 0.08 & -0.05 & 0.02 & 0.43 & 0.17 & -0.01 & 0.14 & -0.02 \\
\hline Second & -0.28 & -0.58 & 0.05 & 0.43 & -0.27 & 0.85 & 0.40 & 0.12 \\
\hline
\end{tabular}

A comparison of the diameters of the zones of growth inhibition revealed that the susceptibilities of all of the strains to the antibiotics monomycin, kanamycin, gentamicin, erythromycin, methicillin, neomycin, and streptomycin were nearly the same. Most of the strains studied were resistant to lincomycin. Low levels of susceptibility to polymyxin (diameters of zones of inhibition, 10 to $18 \mathrm{~mm}$ ) were observed with strains related to $B$. megaterium; this characteristic distinguished these organisms from other species that were completely resistant to this antibiotic. Our data are consistent with previously published data $(3,6-10)$. The specific variations in methicillin susceptibility and streptomycin susceptibility observed previously (6, $10)$ were not confirmed by our results. The levels of susceptibility to these antibiotics varied widely for different strains, as the diameters of the zones of inhibition for methicillin and streptomycin were 16 to 32 and 10 to $24 \mathrm{~mm}$, respectively; however, there was no relationship between this characteristic and species identity.

Considerable interspecific differences in susceptibility were observed with oleandomycin, oxacillin, chloramphenicol, ampicillin, carbenicillin, ristomycin, tetracycline, and benzylpenicillin.

The means and standard deviations for inhibition zone diameters determined for 75 fresh isolates belonging to different Bacillus species are shown in Table 1 . We found that the differences between species were greater than the differences within individual species. Thus, levels of susceptibility to certain groups of antibiotics may be considered suitable characteristics for Bacillus species identification. We found that the levels of interspecific variance calculated for each of eight antibiotics ranged from 70 to $90 \%$ of the whole-sample levels of variance; this was interpreted as being sufficient for adequate species identification.

TABLE 3. Inhibition zone diameters for collection strains

\begin{tabular}{|c|c|c|c|c|c|c|c|c|c|c|c|}
\hline \multirow[b]{2}{*}{ Species or subspecies } & \multirow[b]{2}{*}{ Strain } & \multicolumn{8}{|c|}{ Diam of inhibition zone (mm) with: } & \multicolumn{2}{|c|}{ Coordinates } \\
\hline & & 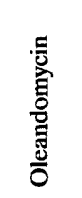 & 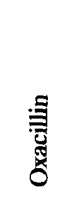 & 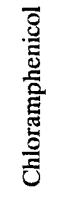 & $\begin{array}{l}\text { 恶 } \\
\text { 容 }\end{array}$ & 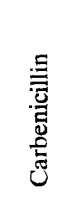 & 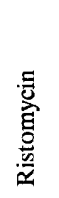 & 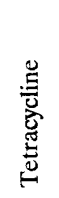 & 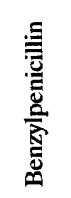 & First axis & Second axis \\
\hline \multirow[t]{5}{*}{ B. subtilis } & ATCC 10774 & 20 & 28 & 28 & 22 & 22 & 16 & 15 & 20 & 15.5 & 5.1 \\
\hline & CCEB 115 & 18 & 30 & 28 & 24 & 25 & 16 & 17 & 21 & 16.9 & 5.5 \\
\hline & VKM 501 & 21 & 27 & 27 & 27 & 28 & 18 & 11 & 20 & 18.2 & 6.0 \\
\hline & VKM 2895 & 22 & 30 & 27 & 25 & 25 & 17 & 19 & 21 & 17.9 & 6.4 \\
\hline & VKM 2896 & 22 & 30 & 28 & 22 & 25 & 17 & 16 & 24 & 16.1 & 4.3 \\
\hline B. subtilis subsp. niger & CCM 110 & 19 & 24 & 18 & 20 & 20 & 18 & 24 & 14 & 15.6 & 11.4 \\
\hline \multirow{5}{*}{ B. licheniformis } & ATCC 14580 & 13 & 17 & 19 & 20 & 20 & 18 & 24 & 14 & 15.5 & 17.2 \\
\hline & CIP 5126 & 13 & 18 & 25 & 19 & 18 & 17 & 28 & 18 & 15.3 & 18.3 \\
\hline & CIP 5829 & $\operatorname{Res}^{a}$ & 13 & 15 & 13 & 15 & 16 & 20 & 10 & 10.6 & 25.1 \\
\hline & IFO 12200 & 12 & 15 & 18 & 19 & 16 & 20 & 26 & 16 & 14.6 & 22.0 \\
\hline & VKM 511 & 15 & 22 & 19 & 19 & 16 & 20 & 26 & 20 & 14.4 & 17.6 \\
\hline \multirow[t]{3}{*}{ B. pumilus } & CCM 2614 & 19 & 20 & 15 & 20 & 28 & 15 & 31 & 30 & 17.8 & 13.6 \\
\hline & СCM 2218 & 20 & 20 & 15 & 26 & 28 & 15 & 29 & 28 & 20.2 & 15.9 \\
\hline & VKM 508 & 18 & 36 & 18 & 42 & 34 & 18 & 36 & 46 & 27.8 & 19.1 \\
\hline \multirow{2}{*}{ B. polymyxa } & ATCC 842 & 14 & 22 & 19 & 24 & 30 & 14 & 25 & 26 & 18.7 & 11.5 \\
\hline & VKM 504 & 14 & 18 & 25 & 23 & 22 & 20 & 20 & 26 & 16.4 & 19.0 \\
\hline B. alvei & VKM 724 & 25 & 28 & 32 & 27 & 30 & 19 & 28 & 29 & 21.1 & 12.7 \\
\hline B. badius & VKM 496 & 25 & 32 & 26 & 40 & 42 & 19 & 22 & 38 & 27.6 & 10.8 \\
\hline \multirow[t]{2}{*}{ B. cereus } & IMV 23570 & 17 & 8 & 22 & Res & Res & 16 & 24 & Res & 8.1 & 16.6 \\
\hline & IMV 211 & 21 & Res & 23 & Res & Res & 15 & 9 & Res & 6.4 & 9.8 \\
\hline B. circulans & VKM 693 & 23 & Res & 22 & 13 & 21 & 18 & 24 & 12 & 14.1 & 17.4 \\
\hline B. laterosporus & VKM 499 & 21 & 30 & 26 & 30 & 31 & 18 & 25 & 27 & 21.7 & 11.1 \\
\hline B. pasteurii & VKM 1063 & 20 & 21 & 20 & 29 & 31 & 16 & 20 & 26 & 20.8 & 12.0 \\
\hline B. pulvifaciens & VKM 748 & 15 & 18 & 24 & 18 & 18 & 19 & 25 & 15 & 14.6 & 17.4 \\
\hline B. macerans & NCIB 1068 & 21 & 15 & 27 & 22 & 30 & 22 & 16 & 32 & 17.4 & 17.1 \\
\hline B. megaterium & KSU 164 & 18 & 24 & 25 & 22 & 22 & 15 & 21 & 20 & 16.3 & 9.4 \\
\hline B. mycoides & IMV 1996 & Res & 19 & 20 & 18 & 15 & 20 & 13 & 17 & 14.4 & 27.0 \\
\hline \multirow[t]{2}{*}{ B. sphaericus } & ATCC 14577 & 18 & 23 & 20 & 25 & 23 & 15 & 39 & 25 & 20.2 & 18.5 \\
\hline & VKM 509 & 13 & 14 & 15 & 10 & 26 & 11 & 17 & 20 & 11.2 & 4.8 \\
\hline B. stearothermophilus & IMV 360 & Res & 17 & 15 & 20 & 14 & 17 & 27 & 10 & 11.9 & 23.8 \\
\hline B. thuringiensis subsp. sotto & VKM 453 & 23 & Res & 29 & 13 & 13 & 20 & 23 & 9 & 12.8 & 20.9 \\
\hline B. thuringiensis & VKM 740 & 17 & 25 & 25 & 32 & 34 & 13 & 19 & 34 & 22.0 & 9.3 \\
\hline
\end{tabular}

${ }^{a}$ Res, resistant. 


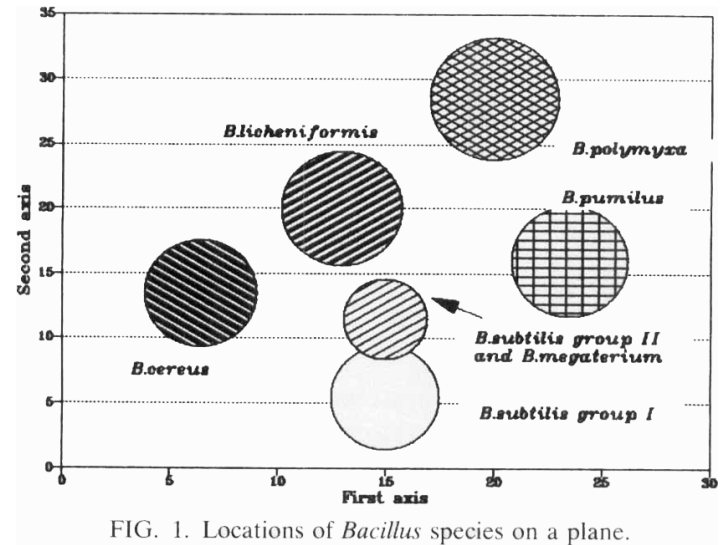

We observed a broad spectrum of values for the levels of correlation between antibiotics, and the correlation matrix formed the database for a principal-component analysis $(2,9)$. Two linear discriminant functions were calculated. The coefficients of these functions are shown in Table 2.

Values for the two linear discriminant functions are equal to the sums of the experimental values multiplied by the corresponding coefficients. For example, to calculate the levels of susceptibility of $B$. subtilis ATCC 10774 to antibiotics (Table $3)$, the first function is $(20 \times 0.08)-(28 \times 0.05)+(28 \times 0.02)$ $+(22 \times 0.43)+(22 \times 0.17)-(16 \times 0.01)+(15 \times 0.14)-$ $(20 \times 0.02)=15.5$, and the second function is $(20 \times-0.28)-$ $(28 \times 0.58)+(28 \times 0.05)+(22 \times 0.43)-(22 \times 0.27)+(16$ $\times 0.85)+(15 \times 0.4)+(20 \times 0.12)=5.1$.

As a result, for each strain we obtained two values which can be considered coordinates of the strain on a plane. A graphic representation of the results of our calculations for all of the strains which we tested is shown in Fig. 1. Six Bacillus species were characterized by defined locations on the plane by using the coordinate limits shown in Table 4 .

To evaluate the method which we used for identification, 32 strains that were assigned to different Bacillus species and were received from some national and private collections were tested by the procedure described above. The data obtained and the decisions reached based on the two discriminant functions are shown in Table 3. The values for B. subtilis ATCC 10774, CCEB 115, VKM 2895, and VKM 2896 were within the ranges obtained for $B$. subtilis strains belonging to group I (Fig. 1 ), and the values for $B$. subtilis subsp. niger CCM 110 were within the ranges obtained for the values for $B$. subtilis group II. Other strains belonging to group II were characterized by slimy growth and dark pigmentation, which distinguished them

TABLE 4. Coordinate limits for Bacillus species on a plane

\begin{tabular}{lrrc}
\hline \multirow{2}{*}{ Taxon } & \multirow{2}{*}{$\begin{array}{c}\text { No. of } \\
\text { strains }\end{array}$} & \multicolumn{2}{c}{ Coordinate limits } \\
\cline { 3 - 4 } & & \multicolumn{1}{c}{ First axis } & Second axis \\
\hline B. subtilis group I & 21 & $14.0-20.0$ & $1.0-8.0$ \\
B. subtilis group II & 7 & $14.0-20.0$ & $10.0-13.0$ \\
B. licheniformis & 10 & $10.0-16.0$ & $15.0-25.0$ \\
B. pumilus & 10 & $19.0-28.0$ & $13.0-19.0$ \\
B. cereus & 10 & $3.0-10.0$ & $10.0-17.0$ \\
B. megaterium & 10 & $14.0-19.0$ & $10.0-13.0$ \\
B. polymyxa & 5 & $15.0-25.0$ & $24.0-33.0$ \\
\hline
\end{tabular}

from strains belonging to $B$. subtilis group I. These strains are probably related to $B$. subtilis subsp. niger.

The locations of the $B$. licheniformis, B. pumilus, B. cereus, and $B$. megaterium strains generally corresponded to the locations shown in Fig. 1, but the locations of $B$. polymyxa ATCC 842 and VKM 504 did not. It is possible that long-term storage of strains ATCC 842 and VKM 504 under laboratory conditions caused substantial changes in them.

Bacillus alvei VKM 724, Bacillus badius VKM 496, Bacillus laterosporus VKM 499, Bacillus pasteurii VKM 1063, Bacillus macerans NCIB 1068, Bacillus mycoides IMV 1996, Bacillus sphaericus ATCC 14577 and VKM 509, and Bacillus thuringiensis VKM 740 could be distinguished clearly from other species by their coordinates on the plane. In contrast, Bacillus circulans VKM 693, Bacillus pulvifaciens VKM 748, Bacillus stearothermophilus IMV 360, and Bacillus thuringiensis subsp. sotto VKM 453 merged with other species.

The method which we describe above is not considered an alternative to other biochemical and physiological tests used for conventional identification of bacilli. However, some significant additional information about taxonomic relationships among Bacillus species may be obtained from analyzing antibiotic susceptibilities.

The data available contain sufficient discriminatory power to allow quick species determinations or at least rough determinations. More precise identifications may be made by tests specific for each species; this should mean that workers can avoid the use of large numbers of biochemical tests for conventional identification.

Furthermore, some closely related species and morphological groups (for instance, $B$. subtilis and B. subtilis subsp. niger) can be differentiated.

Susceptibilities to certain antibiotics evidently reflect other forms of variation in bacilli and adaptation to certain environmental conditions. These relationships are important for understanding the place occupied by these species in microbial associations.

\section{REFERENCES}

1. Bernhard, K., H. Schrempf, and W. Goebel. 1978. Bacteriocin and antibiotic resistance plasmids in Bacillus cereus and Bacillus subtilis. J. Bacteriol. 133:897-903.

2. Brondz, I., I. Olsen, and M. Sjostrom. 1990. Multivariate analysis of quantitative chemical and enzymic characterization data in classification of $A c t i$ nobacillus, Haemophilus and Pasteurella spp. J. Gen. Microbiol. 136:507-513.

3. Burke, W. F. J., and K. O. McDonald. 1983. Naturally occurring antibiotic resistance in Bacillus sphaericus and Bacillus licheniformis. Curr. Microbiol. 9:69-72.

4. Castro, G. R., M. A. Ferrero, B. S. Mendez, and F. Sineriz. 1991. A system for the differentiation of some closely related Bacillus species. J. Biotechnol. 20:105-108.

5. Claus, D., and C. W. Berkeley. 1986. Genus Bacillus Cohn 1872, p. 11051139. In P. H. A. Sneath, N. S. Mair, M. E. Sharpe, and J. G. Holt (ed.), Bergey's manual of systematic bacteriology, vol. 2. The Williams \& Wilkins Co., Baltimore.

6. Coonrod, J. D., P. J. Leadley, and T. C. Eickhoff. 1971. Antibiotic susceptibility of Bacillus species. J. Infect. Dis. 123:102-105.

7. Denis, F., M. Geslin, and A. Nivet. 1975. Sensibilite aux antibiotiques des differents especes de Bacillus (etude de 400 souches). Quest. Sci. Med. 22:16291633 .

8. Jimenez-Valera, M., A. Puiz-Bravo, and A. Ramos-Cormerzana. 1985. Posible interes taxonomico de las pruebas de sensibilidad frente a antibiaticos en el genero Bacillus. Ars Pharm. Rev. Fac. Farm. 26:157-163.

9. Priest, F. G., and B. A. Alexander. 1988. A frequency matrix for the probabilistic identification of some bacilli. J. Gen. Microbiol. 134:3011-3018.

10. Priest, F. G., M. Goodfellow, and C. Todd. 1988. Numerical classification of the genus Bacillus. J. Gen. Microbiol, 134:1847-1882.

11. Rosswall, T., and E. Kvillner. 1978. Principal-component and factor analysis for the description of microbial populations, p. 1-48. In M. Alexander (ed.), Advances in microbial ecology. Plenum Press, New York.

12. Scavizzi, M., L. Stuart, and A. Gordon. 1991. Un modele statistique d'interpretation de l'antibiogramme. C. R. Acad. Sci. Ser. 3 304:325-329. 